\title{
Numerical Simulation on Heat Transfer Characteristics of Water Flowing through the Fracture of High-Temperature Rock
}

\author{
Xiaohu Zhang, ${ }^{1,2}$ Zhaolun Wang, ${ }^{3}$ Yanhua Sun, ${ }^{1}$ Chun Zhu, ${ }^{2,4}$ Feng Xiong, \\ and Qiongqiong Tang ${ }^{4}$ \\ ${ }^{1}$ School of Civil Engineering, Guizhou University of Engineering Science, Bijie 551700, China \\ ${ }^{2}$ State Key Laboratory for Geomechanics and Deep Underground Engineering, Beijing 100083, China \\ ${ }^{3}$ Henan College of Transportation, Zhengzhou, 450006, China \\ ${ }^{4}$ College of Construction Engineering, Jilin University, Changchun 130026, China \\ ${ }^{5}$ School of Civil Engineering, Wuhan University, Hubei 430072, China
}

Correspondence should be addressed to Qiongqiong Tang; 1012846844@qq.com

Received 6 April 2020; Revised 25 May 2020; Accepted 11 June 2020; Published 11 July 2020

Academic Editor: Qian Yin

Copyright (c) 2020 Xiaohu Zhang et al. This is an open access article distributed under the Creative Commons Attribution License, which permits unrestricted use, distribution, and reproduction in any medium, provided the original work is properly cited.

Deep geothermal resources are becoming an increasingly important energy source worldwide. To achieve the optimal efficiency of this resource, the heat transfer characteristics between flowing water and rock need to be further studied. Using the stereotopometric scanning system 3D CaMega, the fracture geometry data of five cuboid granite rocks were obtained to determine the effects of fracture roughness on the heat transferability of rock. A 3-D model was built based upon the scanned geometry data to assess the effects of rock temperature, water velocity, and roughness, and aperture size of fracture surface on the heat transfer coefficient. The simulation tests show that water velocity has the most noticeable effect, followed by aperture size and rock roughness. On the other hand, the initial rock temperature has the least influence. A new heat transfer coefficient was proposed considering aperture size, water flow velocity, and rock fracture roughness. The calculated values of Reynolds, Prandtl, and Nusselt numbers obtained using this coefficient are in good agreement with the numerical simulation results. This study provides a reference for enhancing the heat transfer coefficient to benefit the exploitation of heat energy of hot dry rock.

\section{Introduction}

Clean energy can help solve the problems of air pollution and energy shortages as fossil fuels become exhausted in the coming generations. The deep geothermal energy of hot dry rock (HDR) has been utilized worldwide, including in China [1-3]. China is rich in coal resources and has a well-developed mining system [4-7]. At the same, China is also a vast country with abundant geothermal resources, mostly of the low-medium temperature type. China's geothermal resources potential is about $8 \%$ of the total global geothermal potential (Zhao et al. 2014). Thus, it is necessary to further develop this sustainable energy technology to meet the growing energy demand.
Fluid circulation and heat transmission are essential in conventional or enhanced geothermal systems (Figure 1). Hot water and steam can be extracted from fluids flowing through the fractures found in natural hydrothermal systems. However, dry reservoirs with low permeability require an enhanced geothermal system in which manmade fractures provide a heat exchange surface and pathways for fluids to flow. The existence of fractures is important for affecting the rock mass properties [8-10]. For both natural and man-made fractures, the characteristics of fluid flowing through fractures in the subsurface vary based upon water velocity, surface roughness, temperature, and porosity/permeability characteristics. Further research is needed to accurately model the geothermal 


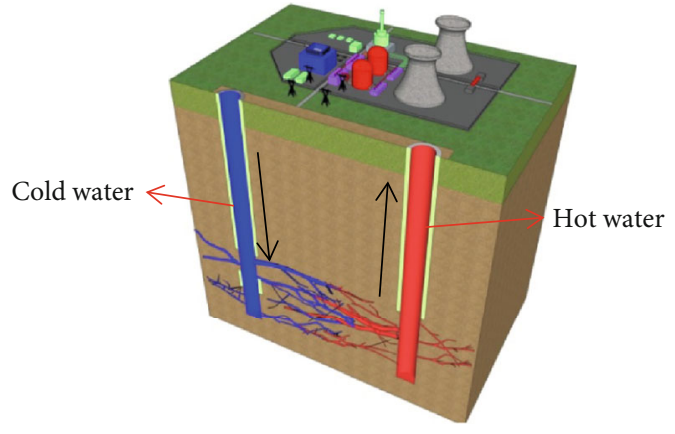

Figure 1: Diagram of a geothermal system.

system in these reservoirs to properly develop geothermal energy.

To explicitly represent the heat transfer of fluid through a fractured surface, a heat transfer coefficient (HTC) was proposed to predict hot water production from an enhanced geothermal reservoir. There has been much in-depth research on this parameter (Zhao et al. 2014; Ganguly et al. 2014; [11-14]; Teke et al. 2018; [15]). For example, Mohais et al. [16] proposed a simplified interpretation and mathematical analysis of flow and heat transfer through a single horizontal fracture in an enhanced geothermal system. Bai et al. [17] proposed an analytical method to develop a more effective equation for the HTC based on the temperature distribution in the fracture wall along the direction of the sample radius. Finally, Abbasi et al. [18] proposed an analytical method to describe the transient temperature distribution in a single fracture model to help investigate water injection into a fractured geothermal reservoir.

Understanding the heat transfer process between fluids and rocks is critical for efficiently exploiting geothermal systems. Many laboratory experiments have been conducted to determine the heat transfer properties of various rock types [19-21]. Huang et al. [22] performed convective heat transfer experiments to study the behavior of water flowing in a simulated rock specimen. Based on two rock specimens with different roughness coefficients, the influence of rock roughness on the seepage characteristics was determined. The secondary damage characteristics of HDR reservoirs were studied through experiments. Guo et al. [23] obtained the damage formulas of granite rock properties based on experimental results.

Although various parameters for specific rock types have been determined, the effects of the flow path and changes in rock temperature on the evolution of fluid temperature have not yet been studied in-depth. Luo et al. [24] used two groups of granite samples with a single fracture obtained from the Gonghe Basin, China, to determine the influence of the flow path. The results showed that the larger the fracture area ratio, the higher the hydraulic conductivity of the rock. Ma et al. [25] created rock samples with different rough surfaces by $3 \mathrm{D}$ printing to study heat transfer of water flowing through rough fractures. They found that the tortuosity of a fracture surface influences local fluctuations in temperature. In another study, distilled water was passed through artificial smooth and rough fractures of rock samples to study the impact of fracture surface roughness on the heat transfer intensity [26]. The results showed that the roughness of the rock fracture surface improves the overall heat transfer intensity to a certain extent. While surface roughness has been studied, the effect of variations in aperture size on heat transfer in geothermal systems has not been extensively studied.

The evaluation of the potential of geothermal energy and accurate prediction of hot water production remains a challenge because of its complexity. As the increasing confining pressure caused by geothermal energy production affects the fracture geometry to some extent, the influence of the aperture size of the fracture on the heat transfer characteristics needs to be studied. While it is known that aperture size affects temperature and production, the increase in aperture size is on the micron level under typical conditions. Therefore, it is difficult to measure the fluid temperature and inner surface temperature at various points along the flow direction in the laboratory or in-situ experiments.

Numerical simulation can easily determine the heat transfer process between water and hot dry rock under the typical complex environment of geothermal reservoirs [27-29]. Kolditz et al. (1998) used a fully 3-D finiteelement model to study the heat transfer during forced water circulation through fractured crystalline rock. The applicability of this model was proven by a 900 -day test at an HDR site in the United Kingdom. Bai et al. [30] built a numerical model to simulate the local heat transfer coefficient (LHTC) of fluid flowing through a single fracture under confining pressure, and the numerical results were verified by test data. To study the coupled thermalmechanical-hydraulic process in fractured porous media, Lee et al. [31] proposed the TOUGH-UDEC numerical software to simulate heat transfer and multiphase fluid flow in fractured porous media. To study the effects of heat transfer between fluid and rock on economic hot water production from geothermal systems, Shaik et al. [32] proposed a numerical approach to simulate the heat transfer process by coupling fluid flow with heat transfer. Most of the previous studies on the heat transfer process are mainly based on 2-D analysis, and influencing factors such as rock temperature, roughness, and aperture size of the fracture surface, and water velocity are not comprehensively considered.

Herein, a 3-D numerical model was adopted to quantitatively investigate the characteristics of the heat transfer process between flowing water and rough granite fracture wall. Rock properties, including rock temperature, roughness, and aperture size of the fracture surface, and water velocity, were included in the model to create a comprehensive heat convection process of water in rock fractures.

\section{Heat Transfer Coefficient}

The heat transfer coefficient is an important parameter that describes the heat transfer characteristics of working fluid flowing through a fractured rock. The average heat transfer coefficient $h$ can be obtained based on energy conservation because the heat absorbed by water in the entire fracture pathway equals the heat transfer by convection between the 
water and the inner surface of the fracture [30]. It can be expressed as follows:

$$
h=\frac{c_{p, w} \rho_{w} v s\left(T_{2}-T_{1}\right)}{2 L\left(T_{i}-T_{1}+T_{2} / 2\right)}
$$

where $c_{p, w}$ is the specific heat capacity of water at constant pressure, $\rho_{w}$ is the density of water, $v$ is the steady flow velocity of water, $s$ is the aperture width, $T_{2}$ and $T_{1}$ are the water temperatures at outlet and inlet ends, respectively, $T_{i}$ is the inner wall temperature of the rock fracture, and $L$ is the length of the rock sample.

Equation (1) requires information on the temperature distribution on the inner wall of the fracture. Here, the formula of the inner wall temperature $T_{i}$ presented by Carslaw and Jaeger (1973) is adopted:

$$
T_{i}=T_{c}-\frac{\pi c_{p, w} \rho_{w} v d s\left(T_{2}-T_{1}\right)}{42.32 K_{r} L},
$$

where $K_{r}$ is the rock thermal conductivity, and $d$ is the equivalent radius of fracture.

Substituting Eq. (2) into Eq. (1), the following equation is obtained:

$$
h=\frac{c_{p, w} \rho_{w} v s\left(T_{2}-T_{1}\right)}{2 L\left(T_{c}-\pi c_{p, w} \rho_{w} v d s\left(T_{2}-T_{1}\right) / 42.32 K_{r} L-T_{1}+T_{2} / 2\right)} .
$$

Compared with previous calculation formulas ([33]; Zhao et al. 1992), this proposed equation does not consider a simplification of specimen section shape. Nevertheless, it can obtain the temperature on the fracture wall by solving the two-dimensional heat conduction equation on a semidisk region.

The Reynolds number Re is calculated as follows:

$$
\operatorname{Re}=\frac{2 q}{d v}
$$

where $v$ is the fluid viscosity, and $q$ is the flow rate.

The Prandtl number $\operatorname{Pr}$ is calculated as follows:

$$
\operatorname{Pr}=\frac{v}{a}
$$

where $a$ is the thermal diffusivity. $a=\lambda / \rho c . \lambda$ is the fluid thermal conductivity coefficient; $\rho$ is water density, and $c$ is fluid specific heat.

The Nusselt number $N u$ is calculated as follows:

$$
N u=\frac{h l}{\lambda}
$$

where $l$ is the characteristic length.

However, the characteristics of rough-walled fracture are not included in most of the established relationships of $\mathrm{Nu}$, Re, and $P r$.

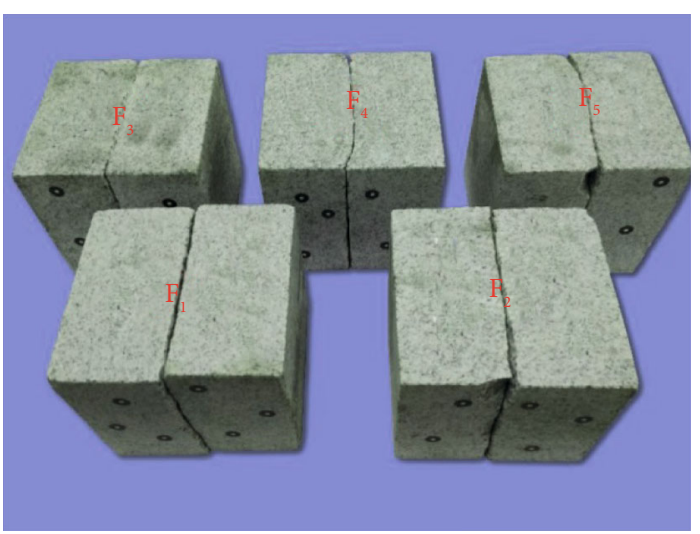

FIGURE 2: Scanned rock samples, each with different roughness values.

\section{Numerical Modeling and Simulation}

It is difficult to directly obtain the temperature inside the fracture surface using microscale sensors. Moreover, the installment of such sensors would affect the natural flow of water through the fracture. Numerical simulation is an effective method to explore the heat transfer process at the microscale. According to the previous research of Bai et al. [30], numerical modeling is an alternative method to obtain the necessary heat transfer characteristics values. Many scholars have studied heat transfer processes primarily based on 2-D analysis, whereas the influencing factors such as rock temperature, roughness, and aperture size of fracture surface along with water velocity have not been comprehensively considered. Based on the previous detailed research [30], COMSOL software was used in this work to study the heat transfer process between the water and fracture surface.

In COMSOL, the single-phase water flow in the fracture follows the Navier-Stokes equations ([34-38]), which can be written:

$$
\begin{aligned}
\nabla \boldsymbol{u} & =0 \\
\rho_{w} \frac{\partial \boldsymbol{u}}{\partial t}+\rho_{w} \boldsymbol{u} \nabla \boldsymbol{u}= & -\nabla p+\nabla\left(\mu\left(\nabla \boldsymbol{u}+(\nabla \boldsymbol{u})^{T}\right)\right. \\
& -\frac{2}{3} \mu((\nabla \boldsymbol{u}) I), \\
\rho_{w} c_{p, w}\left(\frac{\partial T_{w}}{\partial t}+(\boldsymbol{u} \nabla) T_{w}\right)= & -\nabla \boldsymbol{q}_{w},
\end{aligned}
$$

where $\rho_{w}$ is the density, $\boldsymbol{u}$ is the velocity vector, $p$ is the pressure, $c_{p, w}$ is the specific heat capacity, $T_{w}$ is the absolute temperature, and $\boldsymbol{q}_{\boldsymbol{w}}$ is the heat flux vector in water. The heat conduction equation in the rock can be given by:

$$
\rho_{s} c_{p, s} \frac{\partial T_{s}}{\partial t}=-\nabla \boldsymbol{q}_{s}
$$

where $\boldsymbol{q}_{\boldsymbol{s}}$ is the heat flux in rock specimen. The boundary condition of the outlet is the standard atmospheric pressure corresponding to the experiment. 


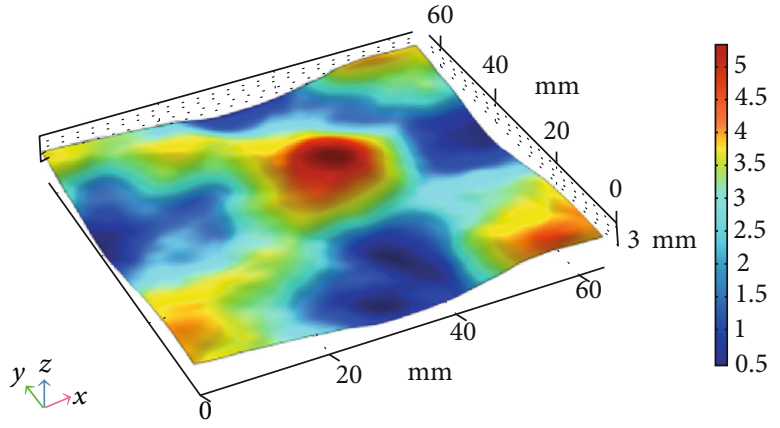

(a) top surface of the fracture in $F_{1}$

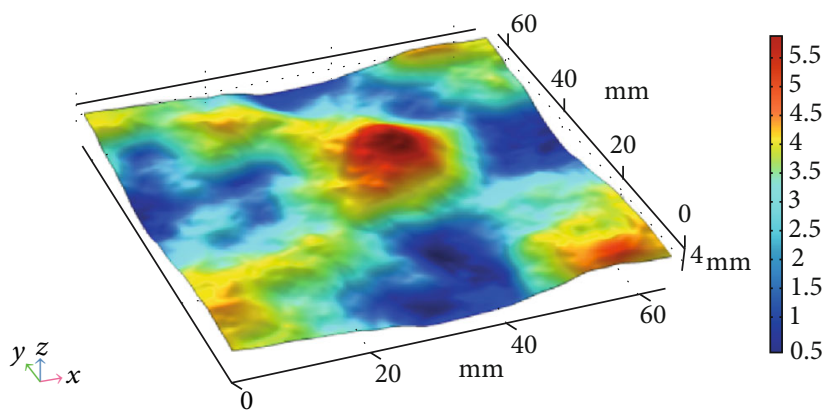

(c) top surface of the fracture in $\mathrm{F}_{3}$

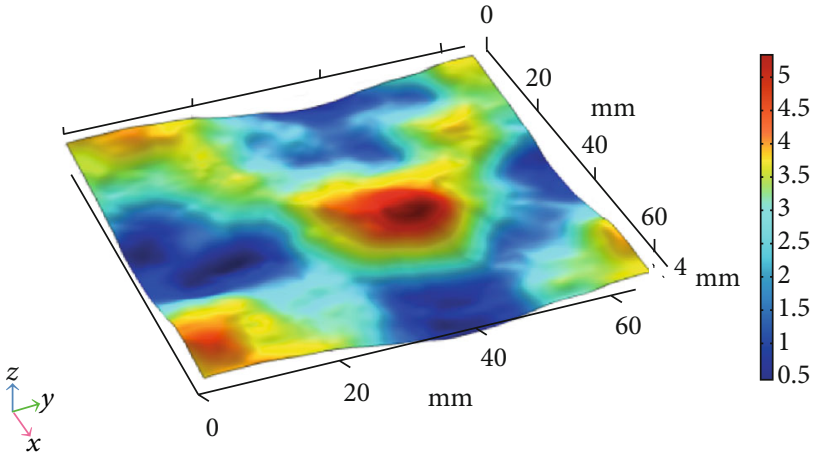

(b) top surface of the fracture in $\mathrm{F}_{2}$

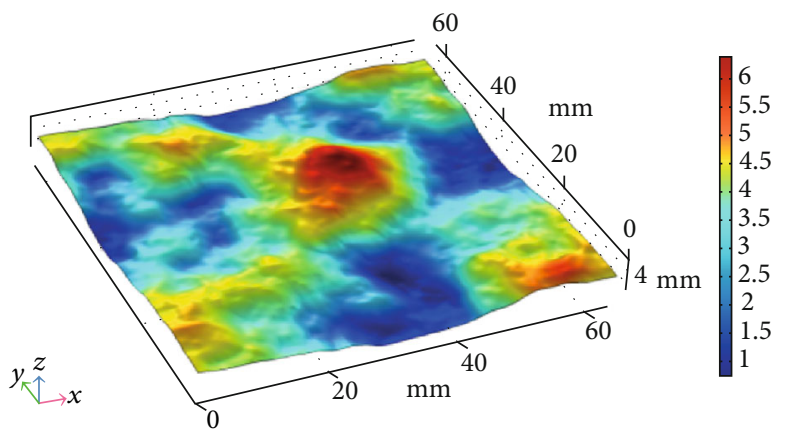

(d) top surface of the fracture in $\mathrm{F}_{4}$

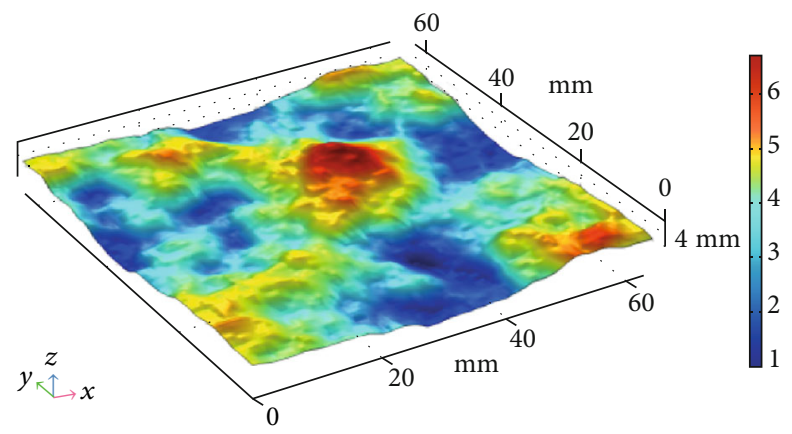

(e) top surface of the fracture in $\mathrm{F}_{5}$

FIgURE 3: 3D discretization of the fracture surfaces in the five samples.

The fracture geometries of five cuboid granite rocks (Figure 2) were obtained through the stereotopometric scanning system 3D CaMega with high measurement speed and precision [34]. The resolution of a sampling point obtained by the scanning system was $\pm 25 \mu \mathrm{m}$, which is defined as the error of 3D space along the $x, y$, and $z$ directions. Roughness measurements were performed on the $64 \mathrm{~mm} \times 64 \mathrm{~mm}$ lower and upper halves of the five fracture replicas. 3D discretization of the fracture surface is shown in Figure 3.

The fracture geometries were then imported into Comsol software. The initial inlet temperature of water was set at $293.15 \mathrm{~K}$. The fractal dimension of the fracture surface $(D)$ for each sample, rock temperature, water velocity, and aperture size of the fracture surface $(s)$ for each simulation are listed in Table 1. The fractal dimension was calculated according to the variogram function of $2 \mathrm{D}$ profiles. More detailed information can be seen in Xiong et al. [34].
The heat transfer process between water and fracture surface was calculated based on the finite element method through precision meshing on these models after setting each simulation parameter of the model in COMSOL. The calculation results of water pressure and rock temperature are plotted in Figure 4, and the calculation results of different heat transfer processes are shown in Table 2.

\section{Simulation Results Analysis}

4.1. Effects of Fracture Aperture Size on the Heat Transfer Characteristics. The distribution of the temperature field is an important indicator of the efficiency of the heat transfer process. The temperature field of water flowing within granite with different aperture sizes $(0.5 \mathrm{~mm}, 0.7 \mathrm{~mm}$, and $0.9 \mathrm{~mm}$ ) was taken as an example, and the effects of fracture aperture size on heat transfer were studied. The flow velocity 
TABLE 1: Fracture parameters influencing the heat transfer coefficient.

\begin{tabular}{|c|c|c|c|}
\hline Fractal dimension $D$ & $\begin{array}{c}\text { Rock temperature } \\
t(\mathrm{~K})\end{array}$ & Velocity of water $v(\mathrm{~m} / \mathrm{s})$ & $\begin{array}{c}\text { Aperture width of fracture } \\
\text { surface } s(\mathrm{~mm})\end{array}$ \\
\hline 1.2 (I rock) & 323.15 & 0.0025 & 0.3 \\
\hline 1.4 (II rock) & 343.15 & 0.0050 & 0.5 \\
\hline 1.6 (III rock) & 363.15 & 0.0075 & 0.7 \\
\hline 1.8 (IV rock) & l & l & l \\
\hline 2.0 (V rock) & l & l & l \\
\hline
\end{tabular}

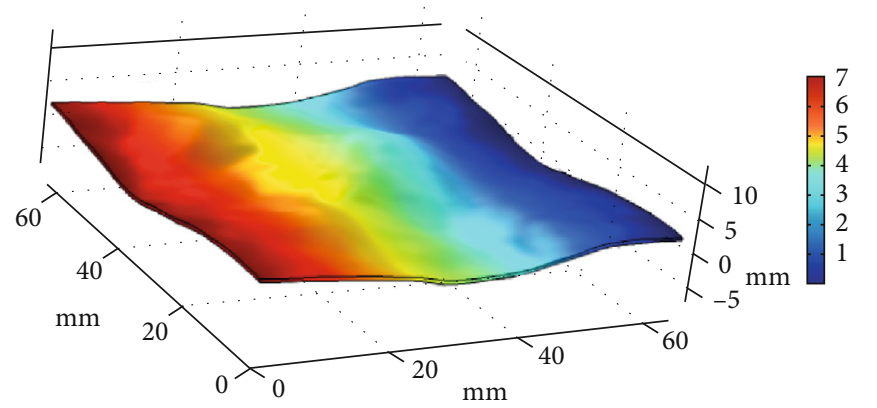

$$
y_{\Re}^{\stackrel{z}{\hookrightarrow} x}
$$

(a)

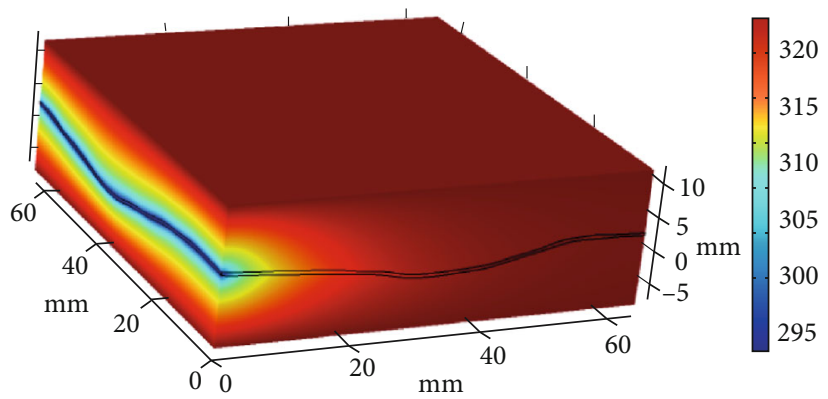

$\underset{r}{\stackrel{z}{\uparrow} \rightarrow x}$

(b)

FIGURE 4: Calculation results of water pressure and rock temperature (Temperature: K).

of water and rock temperature were set as $0.005 \mathrm{~m} / \mathrm{s}$ and $343.15 \mathrm{~K}$, and the 1.4 roughness fracture surface $\left(\mathrm{F}_{2}\right.$ sample) was chosen as the flow surface. The calculation results are shown in Figure 5. Similar temperature trends are observed for the results of the other samples with water flowing through the fracture.

Overall, the aperture size has a significant influence on the heat transfer process (Table 2). As the fracture aperture size increases, the heat transfer coefficient [39-47] increases. When water flows along the fracture surface of a rock, it absorbs the surrounding heat energy of the rock. The temperature of the water gradually increases during the flow process, and the temperature of the surrounding rock decreases slowly along the flow direction. The most significant decrease in temperature occurs at the water inlet. As seen from Figure 5, with the increase in aperture size, the water heating rate decreases and the lower temperature area at the inlet further expands. This is mainly because the increase in aperture size leads to a rise in water flow to maintain a constant flow rate. The total volume of water flowing inside the fracture surface to absorb heat energy increases. Thus, the heat energy stored in the surrounding rock decreases. Overall, the heat transfer coefficient increases.

4.2. Effects of Flow Velocity on the Heat Transfer Characteristics. Using the same rock and aperture size conditions as above, the temperature field of water flowing through granite at different velocities $(0.005 \mathrm{~m} / \mathrm{s}, 0.01 \mathrm{~m} / \mathrm{s}$, and $0.015 \mathrm{~m} / \mathrm{s}$ ) was taken as an example, and the effects of flow velocity on the heat transfer characteristics were studied. The fracture aperture size and rock temperature were set to $0.5 \mathrm{~mm}$ and $343.15 \mathrm{~K}$, and the 1.4 roughness fracture surface $\left(\mathrm{F}_{2}\right)$ was chosen as the flow surface. The calculation results are shown in Figure 6. The results of the other surfaces with varying water velocities exhibit similar trends.

The water velocity has a more significant influence on the heat transfer process than the fracture aperture size (Table 2). With the increase in flow velocity, the heat transfer coefficient markedly increases, although the inner wall temperature and outlet temperature of rock fracture also decrease to some extent. Increase in flow velocity results in an increase in the total volume of water flowing inside the rock to absorb the heat energy. Thus, the heat energy stored in the rock transfers to the water (Figure 6). Finally, the water reaches equilibrium with the rock closer to the outlet with increasing velocity.

4.3. Effects of Rock Temperature on the Heat Transfer Characteristics. At constant water velocity and aperture size of the fracture surface, the effects of rock temperature on the heat transfer characteristics were studied, taking the example of the temperature field of water flowing through granite at different temperatures $(323.15 \mathrm{~K}, 343.15 \mathrm{~K}$, and $363.15 \mathrm{~K})$. The fracture aperture size and flow velocity of 
TABLE 2: Calculation results of different heat transfer processes.

\begin{tabular}{|c|c|c|c|c|c|c|}
\hline Roughness & Aperture (m) & Water velocity $(\mathrm{m} / \mathrm{s})$ & Rock temperature $(\mathrm{K})$ & $\mathrm{Ti}(\mathrm{K})$ & Outlet temperature $(\mathrm{K})$ & Heat transfer coefficient \\
\hline & & & 323.15 & 319.5125 & 323.043 & 107.4001 \\
\hline & & 0.0025 & 343.15 & 337.0955 & 342.985 & 107.4214 \\
\hline & & & 363.15 & 354.6715 & 362.915 & 107.416 \\
\hline & & & 323.15 & 316.0465 & 322.241 & 285.7587 \\
\hline & $5 e-4$ & 0.005 & 343.15 & 331.3185 & 341.65 & 285.8437 \\
\hline & & & 363.15 & 346.5825 & 361.041 & 285.7897 \\
\hline & & & 323.15 & 313.0875 & 320.591 & 543.1123 \\
\hline & & 0.0075 & 343.15 & 326.3865 & 338.903 & 543.4135 \\
\hline & & & 363.15 & 339.6895 & 357.223 & 543.6105 \\
\hline & & & 323.15 & 318.027 & 322.831 & 169.814 \\
\hline & & 0.0025 & 343.15 & 334.6085 & 342.612 & 169.7923 \\
\hline & & & 363.15 & 351.202 & 362.415 & 169.8297 \\
\hline & & & 323.15 & 313.5595 & 320.84 & 484.4274 \\
\hline \multirow[t]{24}{*}{1.2} & $7 e-4$ & 0.005 & 343.15 & 327.1735 & 339.318 & 484.6754 \\
\hline & & & 363.15 & 340.7835 & 357.798 & 484.955 \\
\hline & & & 323.15 & 310.255 & 318.017 & 916.9923 \\
\hline & & 0.0075 & 343.15 & 321.666 & 334.614 & 917.6287 \\
\hline & & & 363.15 & 333.0795 & 351.218 & 918.0965 \\
\hline & & & 323.15 & 316.542 & 322.367 & 245.5782 \\
\hline & & 0.0025 & 343.15 & 332.144 & 341.86 & 245.6567 \\
\hline & & & 363.15 & 347.7375 & 361.334 & 245.6099 \\
\hline & & & 323.15 & 311.4425 & 318.989 & 710.0856 \\
\hline & $9 e-4$ & 0.005 & 343.15 & 323.64 & 336.229 & 710.6735 \\
\hline & & & 363.15 & 335.8445 & 353.481 & 711.0104 \\
\hline & & & 323.15 & 308.11 & 315.376 & 1279.624 \\
\hline & & 0.0075 & 343.15 & 318.09 & 330.212 & 1280.801 \\
\hline & & & 363.15 & 328.063 & 345.021 & 1279.712 \\
\hline & & & 323.15 & 319.5595 & 323.043 & 106.9598 \\
\hline & & 0.0025 & 343.15 & 337.1745 & 342.984 & 106.9772 \\
\hline & & & 363.15 & 354.782 & 362.913 & 106.9723 \\
\hline & & & 323.15 & 316.1265 & 322.261 & 283.5782 \\
\hline & $5 e-4$ & 0.005 & 343.15 & 331.4415 & 341.662 & 283.531 \\
\hline & & & 363.15 & 346.7535 & 361.057 & 283.4858 \\
\hline & & & 323.15 & 313.181 & 320.618 & 536.74 \\
\hline & & 0.0075 & 343.15 & 326.543 & 338.949 & 537.0395 \\
\hline & & & 363.15 & 339.9085 & 357.288 & 537.2532 \\
\hline & & & 323.15 & 317.987 & 322.827 & 170.4365 \\
\hline \multirow[t]{11}{*}{1.4} & & 0.0025 & 343.15 & 334.5415 & 342.605 & 170.4152 \\
\hline & & & 363.15 & 351.1095 & 362.406 & 170.4481 \\
\hline & & & 323.15 & 313.5105 & 320.834 & 487.7402 \\
\hline & $7 e-4$ & 0.005 & 343.15 & 327.0915 & 339.29 & 487.4112 \\
\hline & & & 363.15 & 340.676 & 357.764 & 487.5822 \\
\hline & & & 323.15 & 310.212 & 318.001 & 923.32 \\
\hline & & 0.0075 & 343.15 & 321.594 & 334.586 & 923.8931 \\
\hline & & & 363.15 & 332.979 & 351.18 & 924.4104 \\
\hline & & & 323.15 & 316.5125 & 322.363 & 246.3158 \\
\hline & $9 e-4$ & 0.0025 & 343.15 & 332.094 & 341.853 & 246.4041 \\
\hline & & & 363.15 & 347.6675 & 361.325 & 246.3648 \\
\hline
\end{tabular}


TABle 2: Continued.

\begin{tabular}{|c|c|c|c|c|c|c|}
\hline Roughness & Aperture (m) & Water velocity $(\mathrm{m} / \mathrm{s})$ & Rock temperature $(\mathrm{K})$ & $\mathrm{Ti}(\mathrm{K})$ & Outlet temperature $(\mathrm{K})$ & Heat transfer coefficient \\
\hline & & & 323.15 & 311.4085 & 318.979 & 713.6627 \\
\hline & & 0.005 & 343.15 & 323.5885 & 336.216 & 714.0491 \\
\hline & & & 363.15 & 335.773 & 353.463 & 714.3618 \\
\hline & & & 323.15 & 308.0825 & 315.371 & 1287.704 \\
\hline & & 0.0075 & 343.15 & 318.0445 & 330.202 & 1288.598 \\
\hline & & & 363.15 & 327.999 & 345.008 & 1287.639 \\
\hline \multirow{27}{*}{1.6} & \multirow{10}{*}{$5 e-4$} & \multirow{3}{*}{0.0025} & 323.15 & 319.734 & 323.049 & 105.4043 \\
\hline & & & 343.15 & 337.454 & 342.977 & 105.3962 \\
\hline & & & 363.15 & 355.0385 & 362.755 & 105.401 \\
\hline & & \multirow{3}{*}{0.005} & 323.15 & 316.1165 & 322.141 & 280.7423 \\
\hline & & & 343.15 & 331.4165 & 341.452 & 280.7037 \\
\hline & & & 363.15 & 346.5535 & 360.559 & 280.7069 \\
\hline & & \multirow{3}{*}{0.0075} & 323.15 & 312.981 & 320.29 & 533.38 \\
\hline & & & 343.15 & 326.343 & 338.579 & 533.4634 \\
\hline & & & 363.15 & 339.7085 & 356.888 & 533.9026 \\
\hline & & \multirow{3}{*}{0.0025} & 323.15 & 317.787 & 322.457 & 168.5644 \\
\hline & \multirow{8}{*}{$7 e-4$} & & 343.15 & 334.3415 & 342.195 & 168.9517 \\
\hline & & & 363.15 & 350.9095 & 361.93 & 169.0013 \\
\hline & & \multirow{3}{*}{0.005} & 323.15 & 313.3105 & 320.524 & 485.6311 \\
\hline & & & 343.15 & 326.8915 & 338.97 & 485.8183 \\
\hline & & & 363.15 & 340.476 & 357.425 & 485.9981 \\
\hline & & \multirow{3}{*}{0.0075} & 323.15 & 310.062 & 317.771 & 921.7325 \\
\hline & & & 343.15 & 321.394 & 334.266 & 921.5292 \\
\hline & & & 363.15 & 332.779 & 350.838 & 921.4334 \\
\hline & \multirow{9}{*}{$9 e-4$} & \multirow{3}{*}{0.0025} & 323.15 & 316.3125 & 322.04 & 244.6681 \\
\hline & & & 343.15 & 331.894 & 341.483 & 244.7837 \\
\hline & & & 363.15 & 347.4675 & 360.93 & 244.9673 \\
\hline & & \multirow{3}{*}{0.005} & 323.15 & 311.2085 & 318.669 & 711.0851 \\
\hline & & & 343.15 & 323.3885 & 335.886 & 711.3734 \\
\hline & & & 363.15 & 335.573 & 353.11 & 711.522 \\
\hline & & \multirow{3}{*}{0.0075} & 323.15 & 307.8825 & 315.062 & 1285.096 \\
\hline & & & 343.15 & 317.8445 & 329.88 & 1285.271 \\
\hline & & & 363.15 & 327.999 & 344.99 & 1285.894 \\
\hline \multirow{15}{*}{1.8} & \multirow{9}{*}{$5 e-4$} & \multirow{3}{*}{0.0025} & 323.15 & 319.334 & 322.009 & 100.6993 \\
\hline & & & 343.15 & 337.054 & 341.55 & 100.7489 \\
\hline & & & 363.15 & 354.6385 & 360.855 & 100.4835 \\
\hline & & \multirow{3}{*}{0.005} & 323.15 & 315.7165 & 321.49 & 276.8732 \\
\hline & & & 343.15 & 331.5165 & 341.32 & 276.6828 \\
\hline & & & 363.15 & 346.1535 & 359.659 & 276.2579 \\
\hline & & \multirow{3}{*}{0.0075} & 323.15 & 312.981 & 320.29 & 533.38 \\
\hline & & & 343.15 & 326.343 & 338.579 & 533.4634 \\
\hline & & & 363.15 & 339.7085 & 356.888 & 533.9026 \\
\hline & \multirow{6}{*}{$7 e-4$} & \multirow{3}{*}{0.0025} & 323.15 & 317.387 & 321.7 & 164.5648 \\
\hline & & & 343.15 & 333.9415 & 341.24 & 164.8952 \\
\hline & & & 363.15 & 350.5095 & 360.79 & 164.9999 \\
\hline & & \multirow{3}{*}{0.005} & 323.15 & 312.9105 & 319.9 & 481.101 \\
\hline & & & 343.15 & 326.4915 & 338.3 & 481.6045 \\
\hline & & & 363.15 & 340.076 & 356.7 & 481.7055 \\
\hline
\end{tabular}


TABLE 2: Continued.

\begin{tabular}{|c|c|c|c|c|c|c|}
\hline Roughness & Aperture (m) & Water velocity $(\mathrm{m} / \mathrm{s})$ & Rock temperature $(\mathrm{K})$ & $\mathrm{Ti}(\mathrm{K})$ & Outlet temperature (K) & Heat transfer coefficient \\
\hline & \multirow{12}{*}{$9 e-4$} & \multirow{3}{*}{0.0075} & 323.15 & 309.162 & 316.442 & 919.013 \\
\hline & & & 343.15 & 320.994 & 333.66 & 919.552 \\
\hline & & & 363.15 & 332.379 & 350.23 & 919.9104 \\
\hline & & \multirow{3}{*}{0.0025} & 323.15 & 317.9125 & 323.82 & 240.1812 \\
\hline & & & 343.15 & 331.494 & 340.65 & 240.293 \\
\hline & & & 363.15 & 347.0675 & 360.01 & 240.9346 \\
\hline & & \multirow{3}{*}{0.005} & 323.15 & 310.8085 & 318.078 & 708.5908 \\
\hline & & & 343.15 & 322.9885 & 335.275 & 708.7534 \\
\hline & & & 363.15 & 335.173 & 352.48 & 708.8886 \\
\hline & & \multirow{3}{*}{0.0075} & 323.15 & 307.4795 & 314.167 & 1218.251 \\
\hline & & & 343.15 & 317.4195 & 328.75 & 1218.772 \\
\hline & & & 363.15 & 327.5555 & 343.62 & 1218.943 \\
\hline \multirow{27}{*}{2.0} & \multirow{10}{*}{$5 e-4$} & \multirow{3}{*}{0.0025} & 323.15 & 318.734 & 320.53 & 94.41801 \\
\hline & & & 343.15 & 336.654 & 339.75 & 94.60147 \\
\hline & & & 363.15 & 354.2385 & 358.655 & 94.81679 \\
\hline & & \multirow{3}{*}{0.005} & 323.15 & 315.3165 & 320.82 & 272.4365 \\
\hline & & & 343.15 & 331.1165 & 340.57 & 272.8525 \\
\hline & & & 363.15 & 345.7535 & 358.859 & 272.9349 \\
\hline & & \multirow{3}{*}{0.0075} & 323.15 & 312.581 & 319.68 & 529.4248 \\
\hline & & & 343.15 & 325.843 & 337.79 & 529.5298 \\
\hline & & & 363.15 & 339.3085 & 356.18 & 529.6305 \\
\hline & & \multirow{3}{*}{0.0025} & 323.15 & 316.787 & 320.7 & 160.4109 \\
\hline & \multirow{8}{*}{$7 e-4$} & & 343.15 & 333.3415 & 340.01 & 160.5339 \\
\hline & & & 363.15 & 349.9095 & 359.4 & 160.9596 \\
\hline & & \multirow{3}{*}{0.005} & 323.15 & 312.3105 & 318.99 & 475.5328 \\
\hline & & & 343.15 & 325.8915 & 337.31 & 475.6835 \\
\hline & & & 363.15 & 334.576 & 349.03 & 475.8615 \\
\hline & & \multirow{3}{*}{0.0075} & 323.15 & 308.562 & 315.53 & 913.1465 \\
\hline & & & 343.15 & 320.394 & 332.715 & 913.4476 \\
\hline & & & 363.15 & 331.279 & 348.53 & 913.8874 \\
\hline & \multirow{9}{*}{$9 e-4$} & \multirow{3}{*}{0.0025} & 323.15 & 317.3125 & 322.8 & 234.4315 \\
\hline & & & 343.15 & 330.894 & 339.48 & 234.6153 \\
\hline & & & 363.15 & 346.4675 & 358.61 & 234.7439 \\
\hline & & \multirow{3}{*}{0.005} & 323.15 & 309.6085 & 316.322 & 702.2043 \\
\hline & & & 343.15 & 322.3885 & 334.32 & 702.4912 \\
\hline & & & 363.15 & 334.573 & 351.48 & 702.626 \\
\hline & & \multirow{3}{*}{0.0075} & 323.15 & 306.8795 & 313.26 & 1212.152 \\
\hline & & & 343.15 & 316.8195 & 327.82 & 1212.229 \\
\hline & & & 363.15 & 326.9555 & 342.67 & 1212.526 \\
\hline
\end{tabular}

water were set as $0.5 \mathrm{~mm}$ and $0.005 \mathrm{~m} / \mathrm{s}$, and the 1.4 roughness fracture surface $\left(\mathrm{F}_{2}\right)$ was chosen as the flow surface. The calculation results are shown in Figure 7 . The other samples have similar trends for temperature.

Initial rock temperature has a limited influence on the heat transfer process (Table 2). With the increase in surrounding rock temperature, the water temperature at outlet increases, but the heat transfer coefficient remains essentially constant with only a small increase. The increase in the initial temperature of the rock results in a relatively constant rock temperature (Figure 7). The position where water has a similar temperature as the rock has no obvious deviation and is still near the inlet. Thus, the heat transfer characteristics between flowing water and the rock fracture are not significantly affected by the initial rock temperature. 


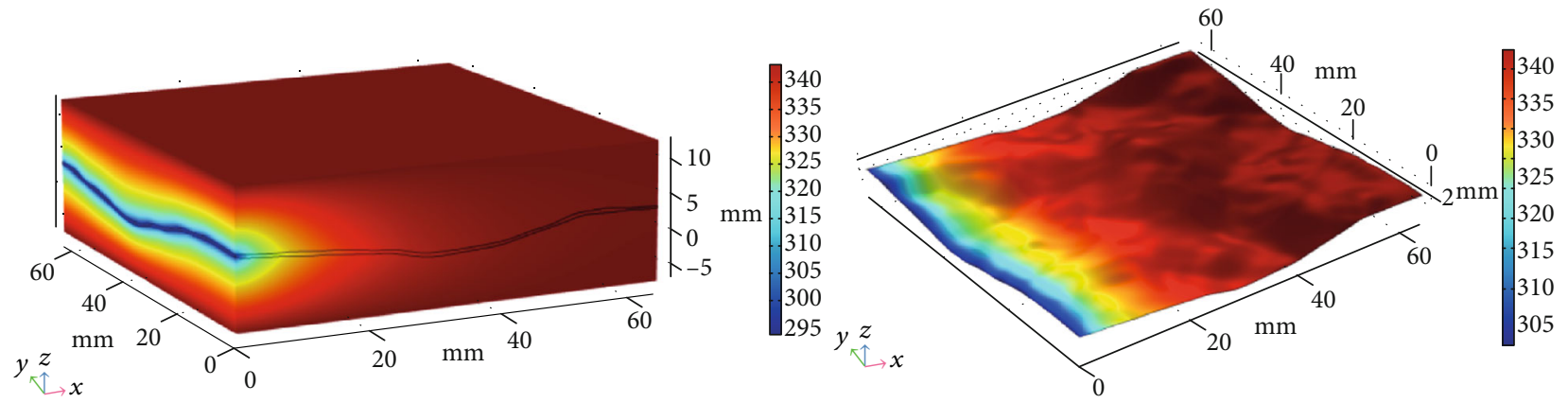

(a) $v=0.005, t=343.15, s=0.5 \mathrm{~mm}, \mathrm{D}=1.4$
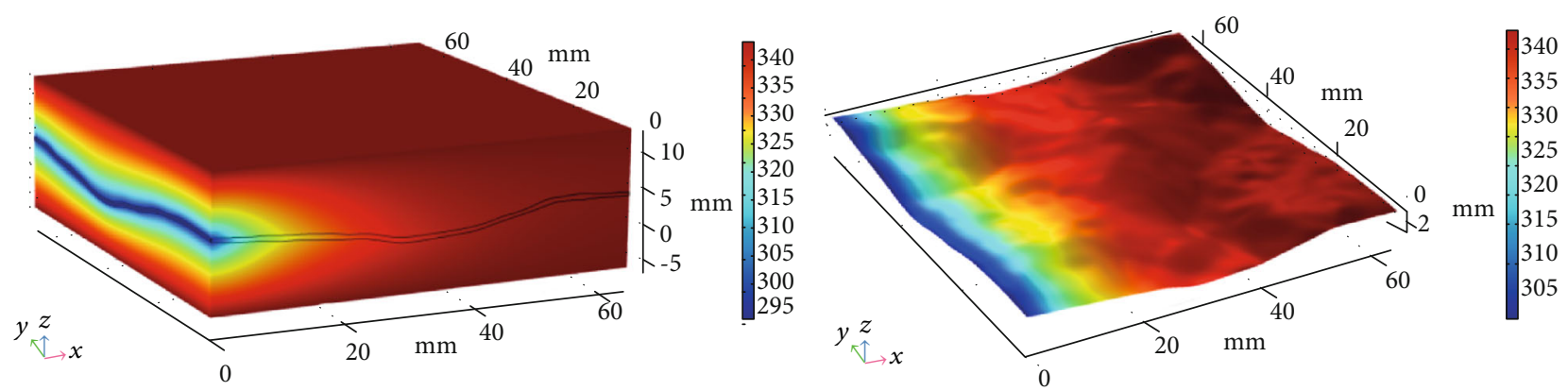

(b) $v=0.005, t=343.15, s=0.7 \mathrm{~mm}, D=1.4$
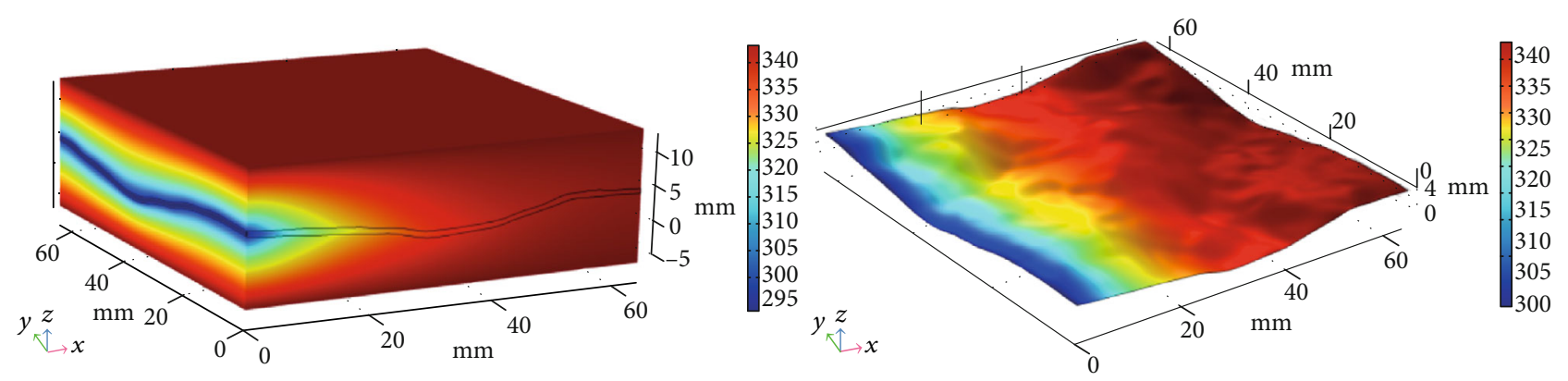

(c) $v=0.005, t=343.15, s=0.9 \mathrm{~mm}, D=1.4$

Figure 5: Temperature field of water flowing through $\mathrm{F}_{2}$ granite sample with various aperture sizes (Temperature: $\mathrm{K}$ ).

4.4. Effects of Fracture Roughness on the Heat Transfer Characteristics. Using constant water velocity, the aperture size of the fracture surface, and initial rock temperature, the effects of fracture roughness on the heat transfer characteristics were studied, taking the temperature field of water flowing through granite rock with different roughness values of fracture surface $(1.2,1.4,1.6,1.8$, and 2.0 roughness fracture surface) as an example. The rock temperature, fracture aperture size, and flow velocity of water were set to $343.15 \mathrm{~K}, 0.5 \mathrm{~mm}$, and $0.005 \mathrm{~m} / \mathrm{s}$, respectively. The calculation results are shown in Figure 8. The other water velocities, aperture sizes, and initial rock temperatures have similar trends.

Fracture roughness has a slight influence on the heat transfer process (Table 2). The increase in fracture roughness results in increased contact area. However, some bumps and recesses in the fracture surface hinder effective heat transfer between flowing water and rock fracture. Overall, the heat transfer coefficient decreases with the increase in the roughness coefficient. An increase in fracture roughness under the same flow velocity, rock temperature, and fracture aperture size results in gradually decreasing heat transfer abilities between flowing water and rock (Figure 8). A greater flow distance is needed to increase and maintain the water temperature at the rock temperature. Thus, the position where water has a similar temperature as the surrounding rock slowly moves towards the outlet. Overall, the decreasing temperature area of the rock becomes relatively large.

\section{Discussion}

To better represent the geothermal system based upon the above results, a new heat transfer coefficient is proposed. Water velocity has the most significant influence on the heat transfer coefficient, followed by fracture aperture size, and 

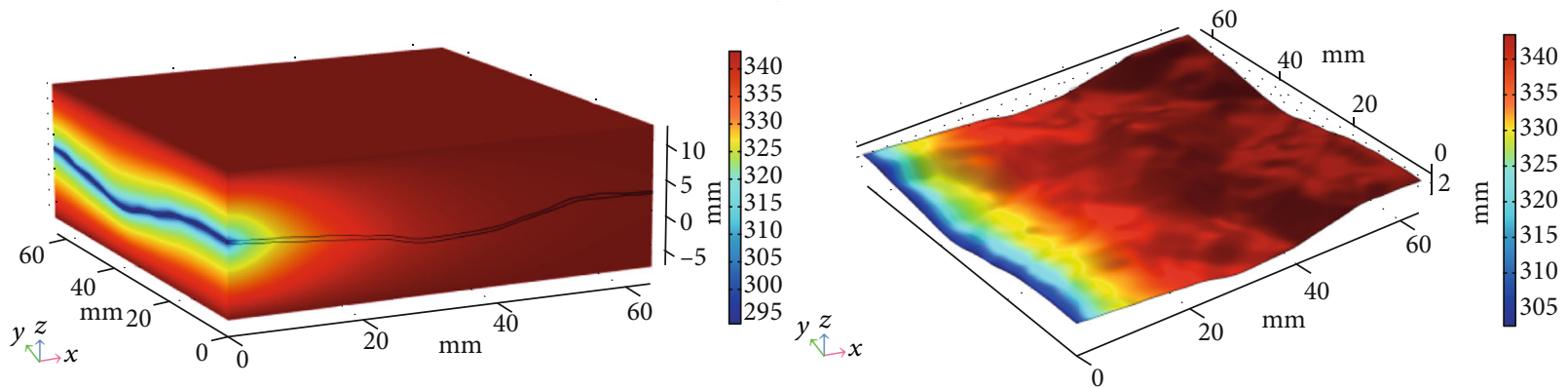

(a) $v=0.005, t=343.15, s=0.5 \mathrm{~mm}, D=1.4$
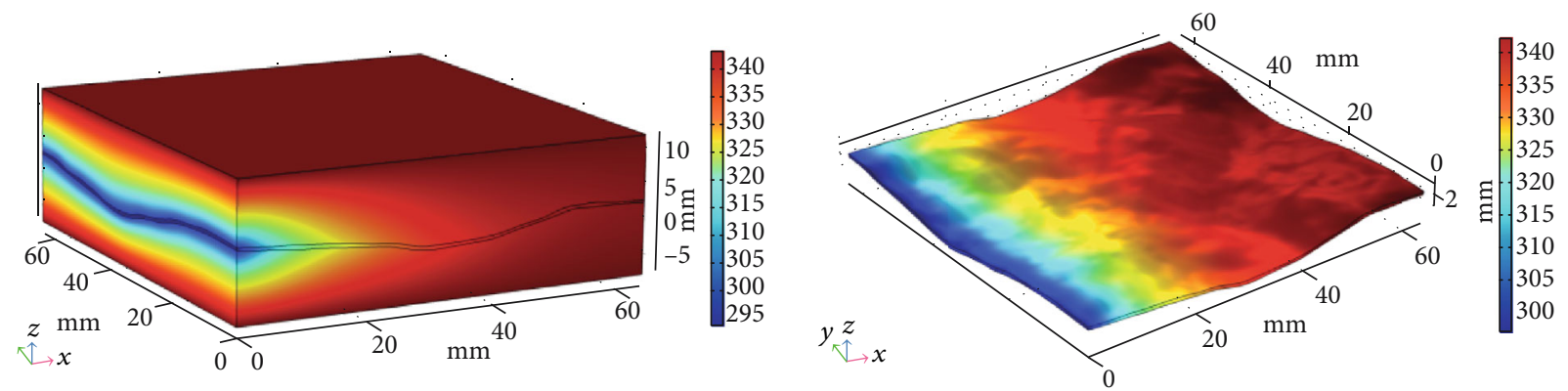

(b) $v=0.010, t=343.15, s=0.5 \mathrm{~mm}, D=1.4$
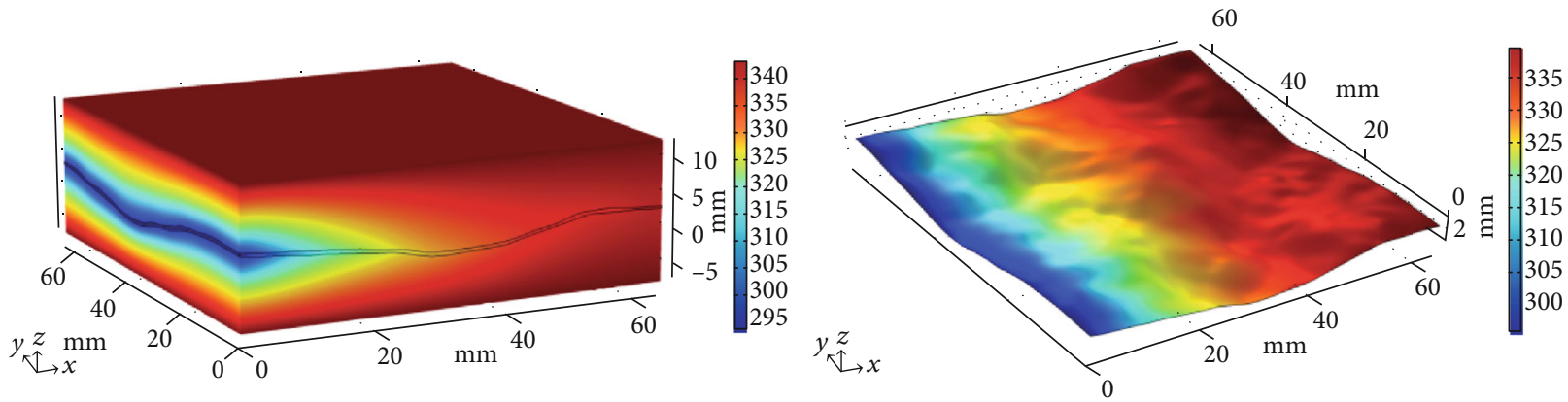

(c) $v=0.015, t=343.15, s=0.5 \mathrm{~mm}, D=1.4$

FIGURE 6: Temperature field of water flowing through granite sample $\mathrm{F}_{2}$ with various velocities (Temperature: $\mathrm{K}$ ).

rock fracture roughness; whereas initial rock temperature has the least influence. Therefore, the initial rock temperature can be ignored in the newly proposed heat transfer coefficient. The new heat transfer coefficient model considers aperture size, flow velocity of water, and rock fracture roughness and can be expressed as:

$$
h=6 \mathrm{e} 9 v^{1.4} \exp (-0.16 D) s^{1.2} .
$$

From Eq. (9), the heat transfer coefficient can be estimated approximately by water velocity, rock fracture roughness, and aperture size. With the increase in the rock aperture size and water velocity, and decrease in the rock fracture roughness, the heat transfer coefficient increases. Therefore, to enhance the heat transfer coefficient of fluid through the rock fracture surface, the water velocity and rock aperture size should be increased appropriately, and the rock fracture surface should be as smooth as possible.

Additionally, the Reynolds, Prandtl, and Nusselt numbers were calculated by Eqs. (4)-(6), respectively. Figure 9 illustrates the positively correlated relationship between the Nusselt number and the Reynolds/Prandtl number ratio. The Reynolds number is within the range of 7.4-20.5 in the above experiments. Based on the characteristics of the curves plotted in Figure 9, a semiempirical relationship between the Nusselt number and Reynolds number/Prandtl number ratio is proposed below in the form of Eq. (10):

$$
N u=0.94 \operatorname{Pr}^{1 / 3} \operatorname{Re}^{1.23}
$$

Figure 9 also presents the best-fitted curves of the numerical data for all the above cases. The results show that Eq. (10) fits well with the experimental data with a high correlation coefficient $\left(R^{2}=0.95\right)$. 

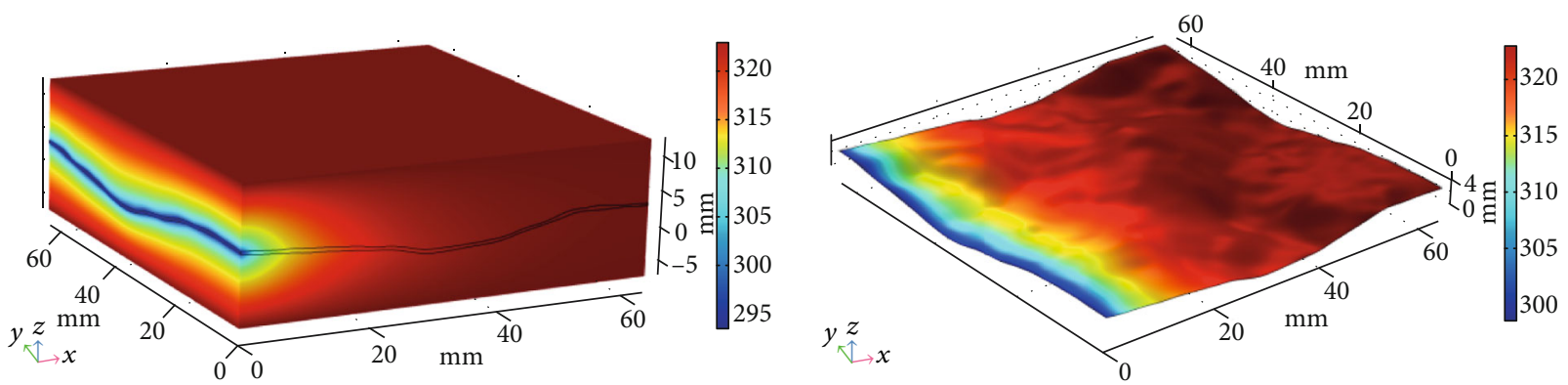

(a) $v=0.005, t=323.15, s=0.5 \mathrm{~mm}, D=1.4$
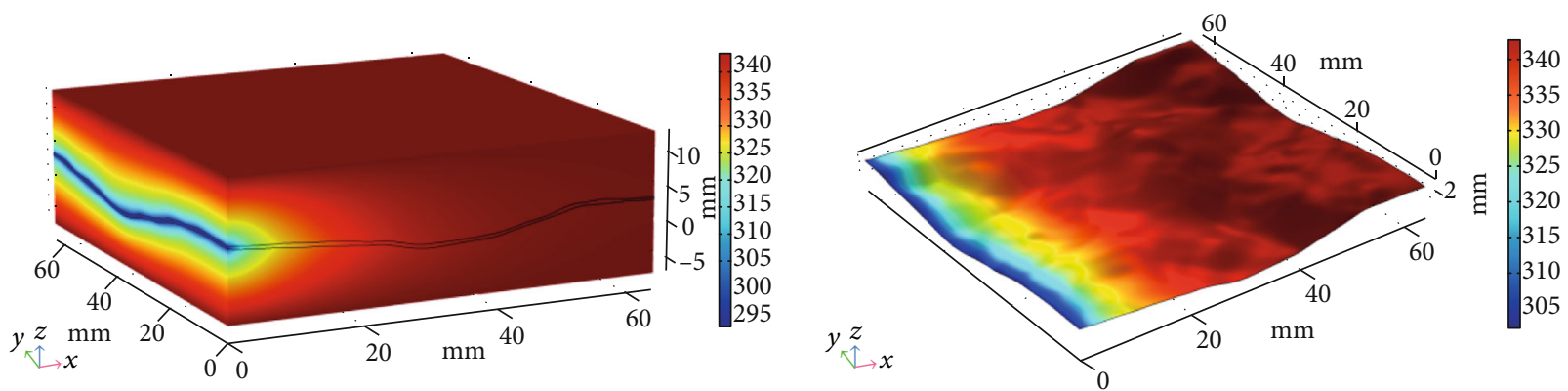

(b) $v=0.005, t=343.15, s=0.5 \mathrm{~mm}, D=1.4$
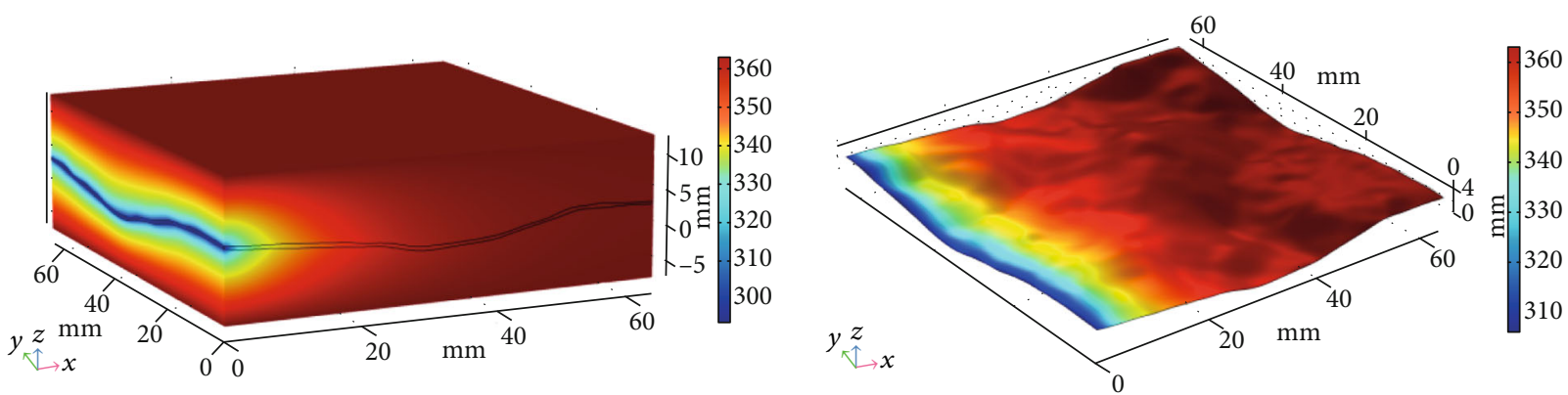

(c) $v=0.005, t=363.15, s=0.5 \mathrm{~mm}, D=1.4$

FIGURE 7: Temperature field of water flowing through a fracture in granite with various starting temperatures (Temperature: K).

Equations (9) and (10) were proposed based on a number of numerical simulations. However, the reliability of numerical simulation results is not acceptable. Hence, a series of heat transfer experiments should be conducted to verify the proposed Eqs. (9) and (10). In addition, the heat transfer coefficient model should be considered for future application in large scale engineering simulation.

\section{Conclusion}

Using a 3-D numerical model, the effects of rock temperature, roughness, and aperture size of fracture surface, and water velocity on the heat transfer characteristics of rock were studied in detail. The following are the main conclusions of this work:

(1) The fracture geometry of five cuboid granite rocks was obtained using 3D CaMega stereotopometric scanning system, and 3-D models were built using
Comsol software by importing the geometry data. Based on previous research, a reasonable 3-D model was built to investigate the effects of rock temperature, roughness, and aperture size of fracture surface, and water velocity on the heat transfer characteristics between flowing water and a rock fracture. The simulation results were highly consistent with previous experimental results, which verifies the precision and practicality of the model

(2) The test results showed that water velocity has the most significant influence on the heat transfer coefficient, followed by fracture aperture size and rock fracture roughness. The initial rock temperature has the least influence. The simulation results provide a foundation for the exploitation of heat energy of hot dry rock for renewable energy resources

(3) A new heat transfer coefficient model was proposed considering aperture size, flow velocity of water, 

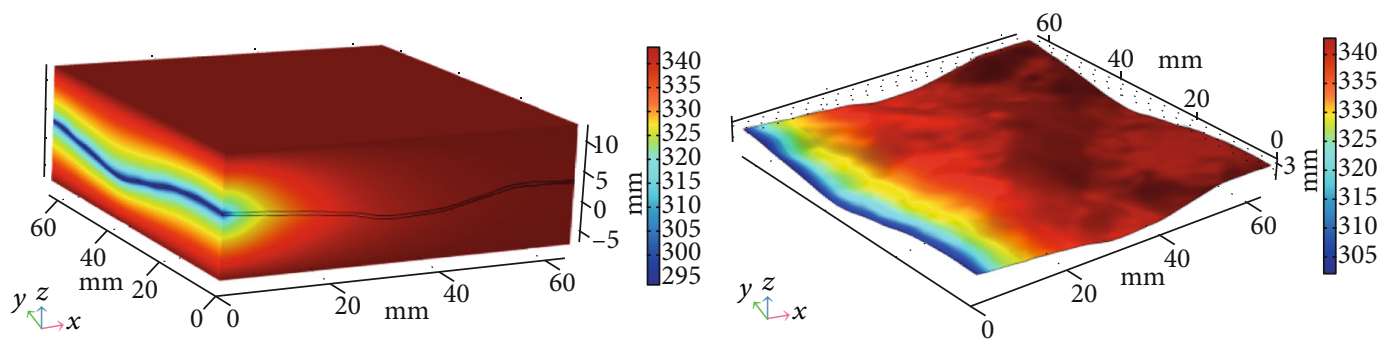

(a) $v=0.005, t=343.15, s=0.5 \mathrm{~mm}, D=1.2$
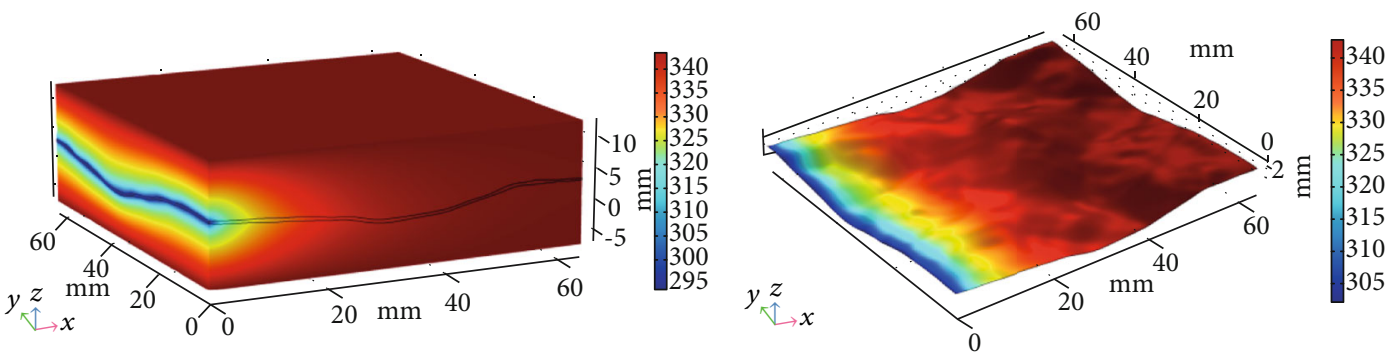

(b) $v=0.005, t=343.15, s=0.5 \mathrm{~mm}, D=1.4$
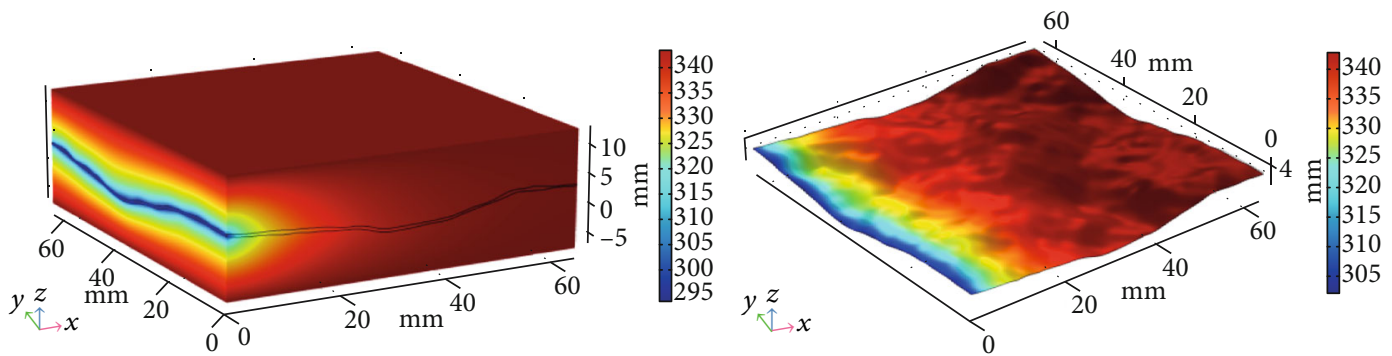

(c) $v=0.005, t=343.15, s=0.5 \mathrm{~mm}, D=1.6$
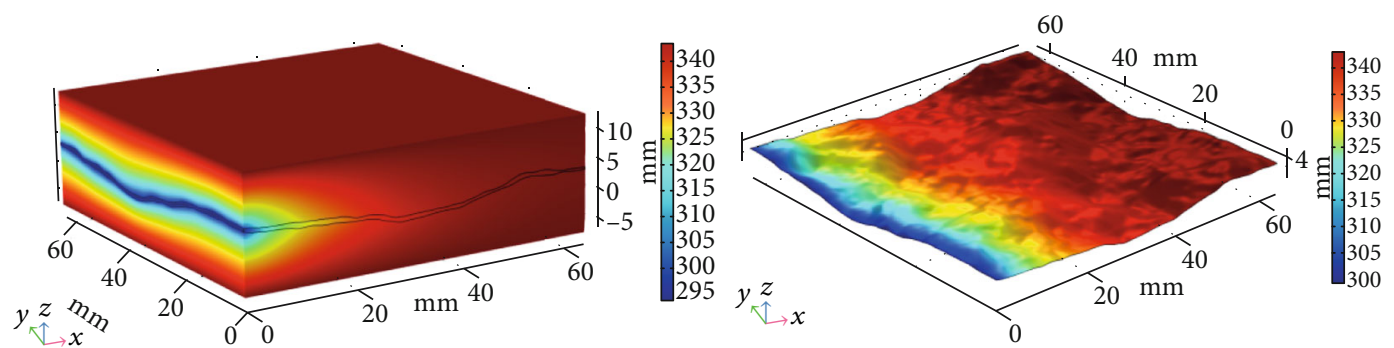

(d) $v=0.005, t=343.15, s=0.5 \mathrm{~mm}, D=1.8$
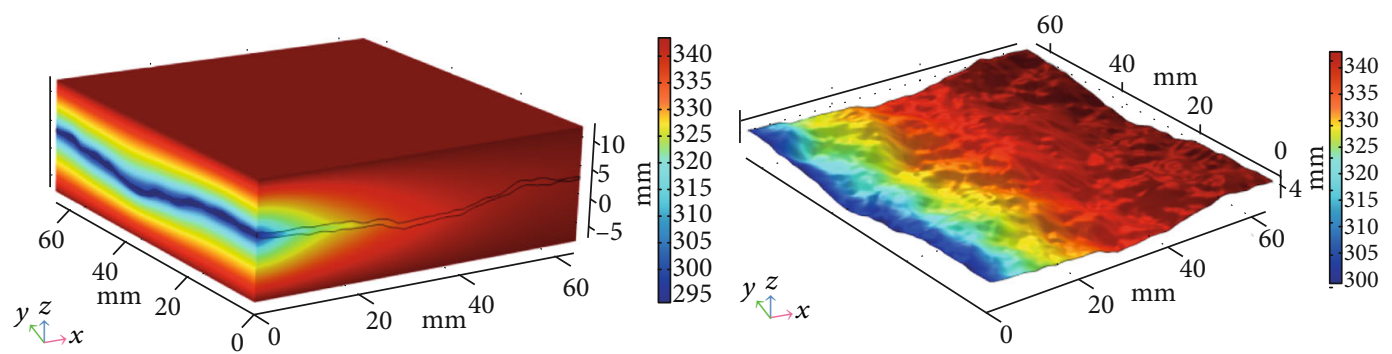

(e) $v=0.005, t=343.15, s=0.5 \mathrm{~mm}, D=2.0$

FIGURE 8: Temperature field of water flowing through granite with various roughness values of fracture surface (Temperature: K).

and rock fracture roughness. The initial rock temperature was not taken into account because it has a negligible effect on the temperature of the water as it passes through the fracture. The heat transfer coefficient can be estimated approximately by the water velocity, rock fracture roughness, and aperture 


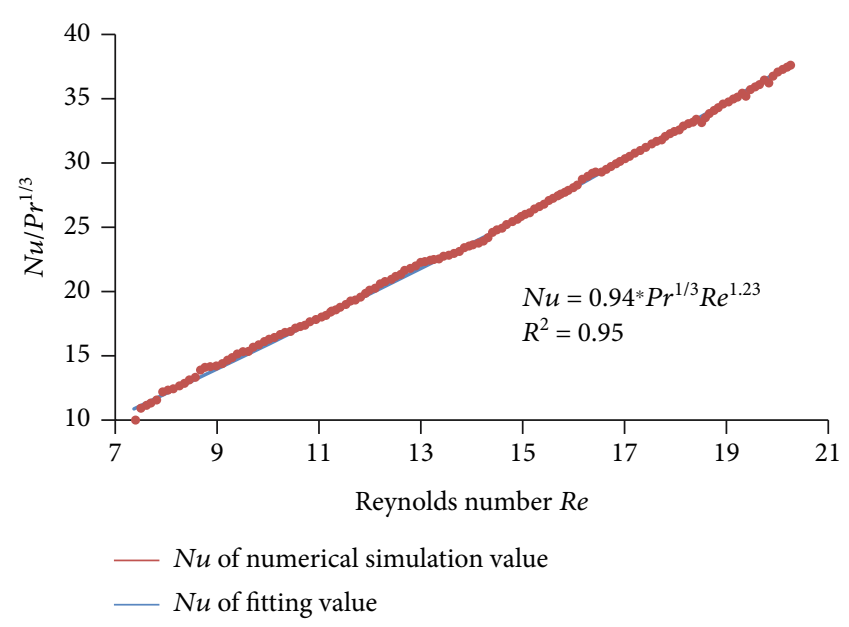

FIgURE 9: The relationship between $\operatorname{Re}$ and $\mathrm{Nu} / \mathrm{Pr}^{1 / 3}$.

size in this new coefficient model. The heat transfer coefficient of water flowing through a fracture in the hot dry rock can be enhanced by increasing the water velocity and aperture size and by decreasing the roughness of the fracture surface. Additionally, a relationship between Nusselt number and Reynolds number/Prandtl number ratio was also proposed based upon the relationships determined through the simulation results

\section{Data Availability}

The data are available and explained in this article, readers can access the data supporting the conclusions of this study.

\section{Conflicts of Interest}

The authors have no conflicts of interest to declare.

\section{Acknowledgments}

This work was supported by the Research and Development Project of Guizhou University of Engineering Science (Grant No: G2018016), the Technology Top Talent Support Project of Guizhou Provincial Education Department ([2017]098), and the Technology Platform and Talent Team Plan Project ([2018]5622).

\section{References}

[1] P. Olasolo, M. C. Juárez, M. P. Morales, S. D’Amico, and I. A. Liarte, "Enhanced geothermal systems (EGS): a review," Renewable and Sustainable Energy Reviews, vol. 56, pp. 133144, 2016.

[2] F. Xiong, Q. Jiang, C. Xu, X. Zhang, and Q. Zhang, "Influences of connectivity and conductivity on nonlinear flow behaviours through three-dimension discrete fracture networks," Computers and Geotechnics, vol. 107, pp. 128-141, 2019.

[3] F. Xiong, W. Wei, C. Xu, and Q. Jiang, "Experimental and numerical investigation on nonlinear flow behaviour through three dimensional fracture intersections and fracture networks," Computers and Geotechnics, vol. 121, p. 103446, 2020.

[4] N. Jiang, C. Wang, H. Pan, D. Yin, and J. Ma, "Modeling study on the influence of the strip filling mining sequence on mining-induced failure," Energy Science \& Engineering, vol. 8, no. 6, pp. 2239-2255, 2020.

[5] J. Wang, J. G. Ning, P. Q. Qiu, S. Yang, and H. F. Shang, "Microseismic monitoring and its precursory parameter of hard roof collapse in longwall faces: a case study," Geomechanics and Engineering, vol. 17, no. 4, pp. 375-383, 2019.

[6] J. Wang, P. Q. Qiu, J. G. Ning, L. Zhuang, and S. Yang, “A numerical study of the mining-induced energy redistribution in a coal seam adjacent to an extracted coal panel during longwall face mining: a case study," Energy Science \& Engineering, vol. 8, no. 3, pp. 817-835, 2020.

[7] N. Wu, Z. Z. Liang, J. R. Zhou, and Y. Z. Zhang, "Energy evolution characteristics of coal specimens with preformed holes under uniaxial compression," Geomechanics and Engineering, vol. 20, no. 1, pp. 55-66, 2020.

[8] G. Feng, Y. Kang, X. C. Wang, Y. Hu, and X. Li, "Investigation on the failure characteristics and fracture classification of shale under brazilian test conditions," Rock Mechanics and Rock Engineering, vol. 53, pp. 3325-3340, 2020.

[9] A. Li, Y. Liu, F. Dai, K. Liu, and M. D. Wei, "Continuum analysis of the structurally controlled displacements for large-scale underground caverns in bedded rock masses," Tunnelling and Underground Space Technology, vol. 97, p. 103288, 2020.

[10] X. Wang, W. Yuan, Y. T. Yan, and X. Zhang, "Scale effect of mechanical properties of jointed rock mass: a numerical study based on particle flow code," Geomechanics and Engineering, vol. 21, no. 3, pp. 259-268, 2020.

[11] J. Dirker, J. P. Meyer, and B. W. Kohlmeyer, "Local heat transfer coefficients at the inlet of an annular flow passage," International Journal of Heat and Mass Transfer, vol. 113, pp. 268280, 2017.

[12] T. Heinze, S. Hamidi, and B. Galvan, "A dynamic heat transfer coefficient between fractured rock and flowing fluid," Geothermics, vol. 65, pp. 10-16, 2017.

[13] Q. Yin, G. W. Ma, H. W. Jing et al., "Hydraulic properties of 3D rough-walled fractures during shearing: an experimental study," Journal of Hydrology, vol. 555, pp. 169-184, 2017.

[14] Q. Yin, H. W. Jing, H. J. Su, and H. Zhao, "Experimental study on mechanical properties and anchorage performances of rock mass in the fault fracture zone," International Journal of Geomechanics, vol. 18, no. 7, 2018.

[15] A. Alkhasov, N. Bulgakova, and M. Ramazanov, "Studies of the heat and mass transfer phenomena when flowing a vaporwater mixture through the system of geothermal reservoirwell," Geomechanics and Geophysics for Geo-energy and Georesources, vol. 6, no. 1, 2020.

[16] R. Mohais, C. Xu, and P. Dowd, "Fluid flow and heat transfer within a single horizontal fracture in an enhanced geothermal system," Journal of Heat Transfer, vol. 133, no. 11, 2011.

[17] B. Bai, Y. Y. He, S. B. Hu, and X. C. Li, "An analytical method for determining the convection heat transfer coefficient between flowing fluid and rock fracture walls," Rock Mechanics and Rock Engineering, vol. 50, no. 7, pp. 1787-1799, 2017.

[18] M. Abbasi, M. Mansouri, A. Daryasafar, and M. Sharifi, "Analytical model for heat transfer between vertical fractures in fractured geothermal reservoirs during water injection," Renewable Energy, vol. 130, pp. 73-86, 2019. 
[19] B. Bai, Y. Y. He, X. C. Li, J. Li, X. X. Huang, and J. L. Zhu, "Experimental and analytical study of the overall heat transfer coefficient of water flowing through a single fracture in a granite core," Applied Thermal Engineering, vol. 116, pp. 79-90, 2017.

[20] L. L. Guo, Y. Zhang, Z. Yu, Z. Hu, C. Lan, and T. Xu, "Hot dry rock geothermal potential of the Xujiaweizi area in Songliao Basin, northeastern China," Environmental Earth Sciences, vol. 75 , no. $6,2016$.

[21] Y. Y. He, B. Bai, S. B. Hu, and X. C. Li, "Effects of surface roughness on the heat transfer characteristics of water flow through a single granite fracture," Computers and Geotechnics, vol. 80, pp. 312-321, 2016.

[22] Y. B. Huang, Y. J. Zhang, Z. W. Yu, Y. Q. Ma, and C. Zhang, "Experimental investigation of seepage and heat transfer in rough fractures for enhanced geothermal systems," Renewable Energy, vol. 135, pp. 846-855, 2019.

[23] L. L. Guo, Y. B. Zhang, Y. J. Zhang, Z. W. Yu, and J. N. Zhang, "Experimental investigation of granite properties under different temperatures and pressures and numerical analysis of damage effect in enhanced geothermal system," Renewable Energy, vol. 126, pp. 107-125, 2018.

[24] J. Luo, Y. M. Qi, Q. Zhao, L. Tan, W. Xiang, and J. Rohn, "Investigation of flow and heat transfer characteristics in fractured granite," Energies, vol. 11, no. 5, p. 1228, 2018.

[25] Y. Q. Ma, Y. J. Zhang, Z. W. Yu, Y. B. Huang, and C. Zhang, "Heat transfer by water flowing through rough fractures and distribution of local heat transfer coefficient along the flow direction," International Journal of Heat and Mass Transfer, vol. 119, pp. 139-147, 2018.

[26] Z. W. Li, X. T. Feng, Y. J. Zhang, C. Zhang, T. F. Xu, and Y. S. Wang, "Experimental research on the convection heat transfer characteristics of distilled water in manmade smooth and rough rock fractures," Energy, vol. 133, pp. 206-218, 2017.

[27] M. Abbasi, N. Khazali, and M. Sharifi, "Analytical model for convection-conduction heat transfer during water injection in fractured geothermal reservoirs with variable rock matrix block size," Geothermics, vol. 69, pp. 1-14, 2017.

[28] T. Lee, K. Kim, K. Lee, H. Lee, and W. Lee, "Development of fluid flow and heat transfer model in naturally fractured geothermal reservoir with discrete fracture network method," Geosciences Journal, vol. 22, no. 3, pp. 477-485, 2018.

[29] P. Popov, G. Qin, L. Bi, Y. Efendiev, R. E. Ewing, and J. Li, "Multiphysics and multiscale methods for modeling fluid flow through naturally fractured carbonate karst reservoirs," SPE Reservoir Evaluation and Engineering, vol. 12, no. 2, pp. 218231, 2013.

[30] B. Bai, Y. He, X. Li et al., "Local heat transfer characteristics of water flowing through a single fracture within a cylindrical granite specimen," Environmental Earth Science, vol. 75, no. $22,2016$.

[31] J. Lee, K. I. Kim, K. B. Min, and J. Rutqvist, "TOUGH-UDEC: a simulator for coupled multiphase fluid flows, heat transfers and discontinuous deformations in fractured porous media," Computers and Geosciences, vol. 126, pp. 120-130, 2019.

[32] A. R. Shaik, S. S. Rahman, N. H. Tran, and T. Tran, "Numerical simulation of fluid-rock coupling heat transfer in naturally fractured geothermal system," Applied Thermal Engineering, vol. 31, no. 10, pp. 1600-1606, 2011.

[33] A. J. Chapman, Heat Transfer, Macmilan publishing company, New York, NY, 4th edition, 1989.
[34] F. Xiong, Q. Jiang, Z. Ye, and X. Zhang, "Nonlinear flow behavior through rough-walled rock fractures: the effect of contact area," Computers and Geotechnics, vol. 102, pp. 179195, 2018.

[35] W. Zheng, S. C. Silva, and D. D. Tannant, "Crushing characteristics of four different proppants and implications for fracture conductivity," Journal of Natural Gas Science and Engineering, vol. 53, pp. 125-138, 2018.

[36] Z. Qin, H. Fu, and X. Chen, "A study on altered granite mesodamage mechanisms due to water invasion-water loss cycles," Environmental Earth Sciences, vol. 78, no. 14, 2019.

[37] Q. Yin, H. W. Jing, G. W. Ma, H. Su, and R. Liu, "Investigating the roles of included angle and loading condition on the critical hydraulic gradient of real rock fracture networks," Rock Mechanics and Rock Engineering, vol. 51, no. 10, pp. 31673177, 2018.

[38] Q. Yin, R. Liu, H. Jing, H. Su, L. Yu, and L. He, "Experimental study of nonlinear flow behaviors through fractured rock samples after High-Temperature exposure," Rock Mechanics and Rock Engineering, vol. 52, no. 9, pp. 2963-2983, 2019.

[39] D. Z Ren, D. S. Zhou, D. K. Liu, F. J. Dong, S. W. Ma, and H. Huang, "Formation mechanism of the Upper Triassic Yanchang Formation tight sandstone reservoir in Ordos BasinTake Chang 6 reservoir in Jiyuan oil field as an example," Journal of Petroleum Science and Engineering, vol. 178, pp. 497505, 2019.

[40] H. Huang, T. Babadagli, X. Chen, H. Z. Li, and Y. M. Zhang, "Performance comparison of novel chemical agents for mitigating water-blocking problem in tight gas sandstones," $S P E$ Reservoir Evaluation \& Engineering, vol. 2020, pp. 1-9, 2020.

[41] S. J. Chen, D. W. Yin, N. Jiang, F. Wang, and Z. H. Zhao, "Mechanical properties of oil shale-coal composite samples," International Journal of Rock Mechanics and Mining Sciences, vol. 123 , article 104120, 2019.

[42] N. Zhang, W. Liu, Y. Zhang, P. F. Shan, and X. L. Shi, "Microscopic pore structure of surrounding rock for underground strategic petroleum reserve (SPR) caverns in bedded rock salt," Energies, vol. 13, no. 4, article 1565, 2020.

[43] Y. Zhang, S. G. Cao, N. Zhang, and C. Z. Zhao, "The application of short-wall block backfill mining to preserve surface water resources in northwest China," Journal of Cleaner Production, vol. 261, article 121232, 2020.

[44] P. F. Shan and X. P. Lai, "An associated evaluation methodology of initial stress level of coal-rock masses in steeply inclined coal seams, Urumchi coal field, China," Engineering Computations, vol. 37, no. 6, pp. 2177-2192, 2020.

[45] H. Y. Wang, A. Dyskin, P. Dight, E. Pasternak, and A. Hsieh, "Review of unloading tests of dynamic rock failure in compression," Engineering Fracture Mechanics, vol. 225, article 106289, 2020.

[46] C. X. Wang, B. T. Shen, J. T. Chen et al., "Compression characteristics of filling gangue and simulation of mining with gangue backfilling: an experimental investigation," Geomechanics and Engineering, vol. 20, no. 6, pp. 485-495, 2020.

[47] W. Zheng and D. D. Tannant, "Influence of proppant fragmentation on fracture conductivity - insights from threedimensional discrete element modeling," Journal of Petroleum Science and Engineering, vol. 177, pp. 1010-1023, 2019. 